\title{
Molecular Regulation of Dendritic Spine Shape and Function
}

\author{
Carlo Sala \\ CNR Institute of Neuroscience, Cellular and Molecular Pharmacology, Department of Pharmacology, \\ University of Milan, Italy
}

\section{Key Words}

Actin · Postsynaptic density · Glutamate receptors •

Synaptic plasticity $\cdot$ Calcium homeostasis

\begin{abstract}
Dendritic spines are discrete membrane protrusions from dendritic shafts where the large majority of excitatory synapses are located. Their highly heterogeneous morphology is thought to be the morphological basis for synaptic plasticity. Electron microscopy and time-lapse imaging studies have suggested that the shape and number of spines can change after long-term potentiation (LTP), although there is no evidence that morphological changes are necessary for LTP induction and maintenance. An increasing number of proteins have been found to be morphogens for dendritic spines and provide new insights into the molecular mechanisms regulating spine formation and morphology.
\end{abstract}

Copyright @2002 S. Karger AG, Basel

Supported by the Giovanni Armenise-Harvard Foundation.

\section{KARGER}

Fax +41613061234

E-Mail karger@karger.ch

www.karger.com
(C) 2002 S. Karger AG, Basel

1424-862X/02/0114-0213\$18.50/0

Accessible online at:

www. karger.com/journals/nsg

\section{Introduction}

Dendritic spines are morphological specializations of neuronal synapses. They are formed by small protruding pieces of membrane with a total volume ranging from less than 0.01 to $0.8 \mu \mathrm{m}^{3}[1,2]$ and contain $90 \%$ of the excitatory synapses in mature brain. Spines were first observed by the Spanish neuroscientist Ramon y Cajal [3] using the Camillo Golgi 'reazione nera' protocol and, since then, many scientists and neuroscientists have tried to understand their cerebral function. Most of the principal glutamate- or GABA-releasing neurons (such as the pyramidal and Purkinje neurons), but not many other neuron classes (such as GABA-releasing interneurons), have synapses on dendritic spines. Dendritic spines are present at the squid giant synapses [4] but are rarely found in other lower organisms (such as Drosophila melanogaster or Caenorhabditis elegans), suggesting that they may have developed early in evolution in order to implement more complex nervous system functions. This review focuses on the cellular and molecular mechanisms that regulate spine shape and function. Recent knowledge on molecules that regulate spine morphology is also improving our understanding of their roles in brain plasticity and function.

Via Vanvitelli, 32, I-20129 Milan (Italy)

Tel. +3902 50317096, Fax +3902 7490574, E-Mail c.sala@csfic.mi.cnr.it 

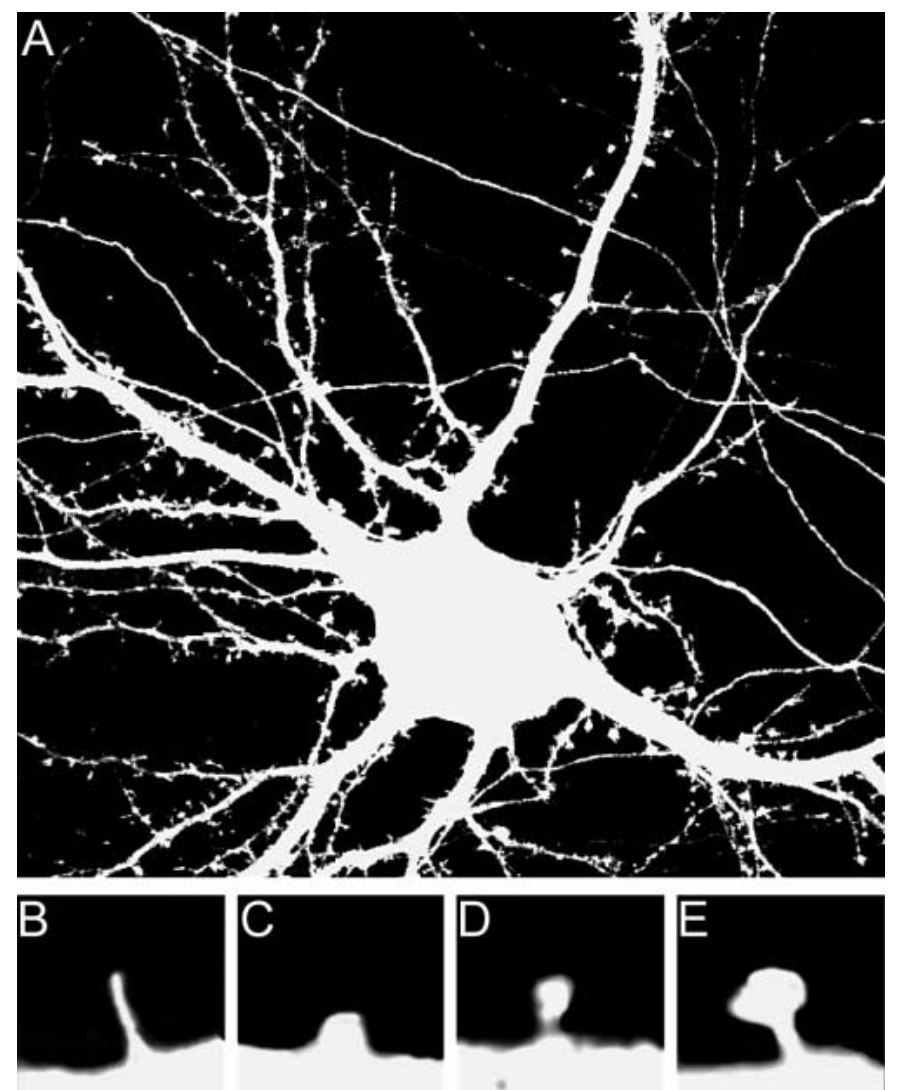

Fig. 1. Dendritic spine morphology can be observed in a hippocampal neuron transfected with GFP. A Low magnification of a GFPtransfected hippocampal neuron in culture. B-E Examples of different dendritic spine shapes viewed at high magnification: filopodium (B); stubby spine (C); thin spine (D), and mushroom-shaped spine (E).

\section{Structure and Development of Dendritic Spines}

Although spines may have different shapes, they are essentially formed by a neck and head attached to the dendritic membrane. Extensive electron microscopy studies of brain tissue have shown that they may be thin, stubby, mushroom-shaped or cup-shaped (fig. 1) [1,5-8] and that these different shapes can be found at the same time with the same dendrites [2,9]. This crude classification underlines the multiple forms and dimensions of the spinal head and neck: the classic mushroom-shaped spines have a large head and narrow neck, whereas thin spines have a smaller head and narrow neck and stubby spines show no obvious constriction between the head and its attachment to the dentritic shaft. However, this static view does not reflect the real in vivo situation because at least in devel- oping neurons, about $50 \%$ of the spines change their shape over periods of minutes or hours and the other $50 \%$ retain their morphological classifications [10]. Spine motility is developmentally regulated and, in mature neurons, there are fewer transitions between categories [10, 11]. The fixed structures observed through an electron microscope are therefore probably a representative picture of spines at that particular moment during a possible morphological transition. In the brain, spines and presynaptic boutons are surrounded by glial cells in such a way as to form an intercommunicating tripartite complex and at least half of the circumference of about $57 \%$ of the synapses is covered by astrocyte processes [12]. Typical mature spines have a single excitatory synapse located at the head, but the same spines can also have an inhibitory input $[13,14]$. However, spines essentially represent the main unitary postsynaptic compartment for excitatory input.

Remarkable differences can also be seen in the intracellular composition of each spine which consists of the postsynaptic density (PSD) facing the presynaptic button and a cytoskeletal structure mainly formed by F-actin. About $50 \%$ of the spines on hippocampal CA1 cells and virtually all Purkinje cell spines also have a smooth endoplasmic reticulum (SER) [15], some pyramidal cell spines contain the spine apparatus, an organelle formed by two or more disks of SER separated by electron-dense material [16]. Large spines usually have a proportionally large synapse and contain different organelles. Both the SER and spine apparatus are usually associated with larger spines and are formally absent in small spines [15]. As SER is known to play a role in $\mathrm{Ca}^{2+}$ handling $[17,18]$ differently sized spines may have different ways of controlling calcium homeostasis (see below). The final components are ribosomes in which proteins can be specifically synthesized in close relationship with each spine. Polyribosomes are frequently found in the spines of different neuron subtypes $[19,20]$.

PSD is an electron-dense thickening of the membrane usually found at the head of the spine, where the synaptic junction is located. It usually occupies about $10 \%$ of the surface area exactly opposite the presynaptic active zone, and is the site for the $\alpha$-amino-3-hydroxy-5-methyl-4isoxazole propionic acid (AMPA) and N-methyl- $D$-aspartate (NMDA) glutamate receptors. The PSD is probably the most complex spine organelle in which hundreds of components (including receptors, cytoskeletal and adapter proteins, and associated signaling molecules) are involved in a number of signaling pathways controlling synaptic plasticity [21, 22]. Proteins are associated with 
each other in a complex based on a series of protein-protein interaction domains of which the PDZ domain is one of the most important [23].

Three immunogold-labeling studies of the hippocampus [24-26] have shown that the number of AMPA and NMDA receptors is proportional to the PSD area and spine volume because their density is constant within the PSD. The PSD and spine volume are also proportional to the area of the active zone, which is itself proportional to the number of docked vesicles [27], which in turn correlates with the amount of neurotransmitter release per action potential [28]. All of these data suggest that large spines represent stronger synapses for both presynaptic and postsynaptic properties, and that the growth of the spine head during development probably correlates with a strengthening of synaptic transmission.

Three-dimensional reconstructions of the PSD show that it may have a number of shapes: as macular (i.e., plaque-like and uninterrupted) or perforated (i.e., fenestrated appearance), horseshoe-shaped or segmented. Interestingly, perforated PSDs have been consistently found to be associated with more AMPA receptor immunoreactivity than non-perforated PSDs [24]. The mushroomshaped and largest spines are more likely to contain perforated PSDs [29], whereas virtually all thin spines have macular PSDs [8]. The shape of the PSD is not fixed and may change with modifications in the strength of synaptic activity, such as during long-term potentiation (LTP) [3032]. Perforated PSDs may reflect enhanced AMPA receptor insertion into the postsynaptic membrane (which occurs during synaptic potentiation or growth) as an early phase of synapse duplication and spine division, or may be the morphological correlate of the enhanced receptor turnover at the PSD that might occur during LTP [3339].

In adult hippocampal CA1 pyramidal and granule cells, dendritic spine density ranges from two to four spines per micrometer of dendrite [8,29, 40, 41], whereas it is more than ten spines per micrometer in Purkinje cells $[42,43]$. The density is lower in dissociated cultures of hippocampal neurons usually being 3-4 spines for each $10 \mu \mathrm{m}$ of dendrites [44] (fig. 1A). The two-dimensional nature of cultured neurons provides a viable and convenient means of studying the factors regulating the development and functions of dendritic spines. In the brain, the density of spines is not homogeneous throughout the dendritic tree but increases at each layer, thus suggesting that the afferent system independently regulates different parts of the dendritic tree [45, 46]. Spine density also varies across cortical areas. Apparently, in macaque monkeys and humans the density on basal dendrites in the cortical areas of the frontal pole and orbitofrontal cortex is generally higher than in neurons of the primary visual and somatosensory cortices [47, 48], and it has been hypothesized that there may be a link between spine density and overall number and level of cortical processing in these regions. Although not totally proved, it is believed that these 'higher' order areas are involved in a greater degree of convergent processing, which may create a need for more synapses and therefore more spines.

How are mature spines formed? Early spines are often very long and have frequent filopodia-like shape (fig. 1B) but, later during development, their mean length decreases and the number of filopodia is greatly reduced. Three major changes can be observed during the maturation process: an increase in spine density; a decrease in overall length, and a decrease in the number of dendritic filopodia with a simultaneous decrease in spine motility $[11,49]$. Recent studies have shown that filopodia rapidly protrude and retract from dendrites, especially during the early stages of synaptogenesis [50-52], and it is widely believed that dendritic filopodia are the precursors of dendritic spines, various hypotheses as to how the transition from filopodia to spines takes place have been put forward.

In the first proposed model, filopodia actively seek out synaptic partners in the developing neuropil and when a filopodium makes contact with an axon, it becomes shorter and draws the axonal terminal closer to the dendrite shaft. Subsequently, a fully mature synapse is formed on the spine head, spine motility gradually decreases and the structure is stabilized [50-52]. However this model does not explain why the density of asymmetric synapses is much higher on dendritic shafts than on filopodia during early development [50,53]. Another model has proposed that, after their contacts with axons, the filopodia retract completely, thus leading to the formation of an asymmetric shaft synapse from which a spine emerges with a mature synapse at its head [2, 50]. In a recent study using two-photon time-lapse microscopy, Parnass et al. [10] demonstrated that stubby and other types of spines can originate from filopodia in developing hippocampal neurons and, depending on the state of the afferent input, spines turning into filopodia were also observed. In this model a filopodium is like a spine in a state of morphological instability and is not a necessary intermediate for spine formation. In other words, the transition from filopodia to spines is less likely to be predestined than a reversible process regulated by local factors, such as synaptic activity. 
In two recent time-lapse studies spine morphogenesis and PSD-95 fused to green fluorescent protein (GFP), a PSD marker, were simultaneously imaged. In both cases the authors suggested that synapses initially form on dynamic filopodia-like spines that soon convert directly into stable spines at the same time as the formation of postsynaptic specialization [54, 55]. However, only Marrs et al. [54] showed the emergence of stable spines from shaft synapses.

Overall, these data suggest that it is probably still incorrect to assume that all spines go through the same stages (beginning as filopodia, proceeding to thin or stubby spines, and ending as mushroom spines), and that spine maturity does not necessarily correlate with spine morphology.

\section{Spine Function and Morphogenic Spine Molecules}

What is the function of dendritic spines in synaptic transmission? The currently prevailing opinion is that the spine may function as a microcompartment for segregating postsynaptic chemical responses [56, 57]. There is no clear evidence that spines work as electrical compartments [57], at least in the case of CA1 synapses [58]. Interestingly, the shape of the spine neck might control postsynaptic calcium responses: in spines with long necks $\left[\mathrm{Ca}^{2+}\right]$ rises faster and decays slower than in those with short necks $[59,60]$, and spine motility induces modifications in neck length that correlate with altered calcium kinetics within the spine [61, 62, but see also 63].

In two papers $[63,64]$ it has recently been proposed that $\left[\mathrm{Ca}^{2+}\right]$ in spines may regulate the activation of LTP or LTD induced by NMDA receptor stimulation. The different kinetics of spine calcium concentration obtained using different stimulation protocols might activate CAMKII and LTP or calcineurin and LTD [63]. Differences in $\left[\mathrm{Ca}^{2+}\right]$ kinetics and synaptic plasticity also depend on the location of the spines along the dendritic tree [64], [ $\left.\mathrm{Ca}^{2+}\right]$ decay is faster on distal spines whose synapses are less susceptible to depression. Under physiological conditions, the spine neck acts as a barrier to diffusion and its head is isolated from the dendrite during an action potential. Spines can act as semi-autonomous chemical compartments separated from the dendritic shaft by a thin neck of up to a few micrometers in length. In brief, they can compartmentalize calcium and other second messengers (such as $\mathrm{IP}_{3}, \mathrm{cAMP}$ and cGMP), and this function is regulated by their morphology. However, their physiological signifi- cance for brain function will probably remain a major unresolved question until all of the molecular mechanisms regulating spine formation and morphology have been clarified.

Considerable efforts have recently been made to characterize the molecular mechanisms controlling spine morphology, formation and plasticity (fig. 2). Most of these studies were carried out using cultured neurons in which putative molecules were overexpressed and the modifications in spine morphology were observed using GFP overexpressed protein. Few molecules have been analyzed in genetic experiments. One of these, the fragile $\mathrm{X}$ mental retardation protein (FMRP) has a direct connection with a human pathology, in which its deletion is responsible for severe mental retardation. An abnormal density of dendritic spines has been observed in human patients affected by the fragile $\mathrm{X}$ syndrome $[65,66]$. In $\mathrm{KO}$ mice with the Fmrl gene, the number and length of dendritic spines are greater than in normal animals [67], especially during the first 2 weeks after birth when the spines develop [49]. FMRP is an mRNA-binding protein that may regulate the synthesis of the molecules involved in the developmental stabilization, elimination or pruning of dendritic spines or synapses.

Defects in spine morphology during the development process have been observed in two other $\mathrm{KO}$ animals, one for the NR3A and the other for spinophilin. The NR3A KO mice show enhanced NMDA responses associated with increased spine density during early postnatal development [68]. Similarly, a marked increase in spine density during development in vivo and altered filopodial formation in cultured neurons have been observed in spinophilin KO mice [69].

As filamentous actin (F-actin) is the main constituent of the cytoskeleton of dendritic spines, actin-binding proteins are likely to be involved in spine formation and shape [70]. A number of actin-binding proteins are highly localized to spines: $\alpha$-actinin [71], drebrin [72], spinophilin/neurabin II [73], SPAR [74], adducin [75], synaptopodin [76] and cortactin [77]. There is evidence that some of them are involved in regulating spine morphology. We have already mentioned spinophilin KO mice [69]. Hayashi and Shirao [72] have shown that the overexpression of drebrin in cultured cortical neurons (whose localization to spine depends on the actin-binding domain) induces a statistically significant elongation of dendritic spines. However, how drebrin or spinophilin regulates actin dynamics is still not totally clear.

Small GTPases of the RHO/RAC/CDC42 family are regulators of the actin cytoskeleton in many cell types. 
Fig. 2. Schematic representation of a mushroom-shaped spine and some of the proteins within the PSD and postsynaptic membrane that regulate spine morphology. NMDAR = $\mathrm{N}$-Methyl- $D$-asparate receptor; $\mathrm{AMPAR}=$ AMPA receptor; $\mathrm{F}$-actin $=$ filamentous actin; GKAP = guanylate-kinase-associated protein; Kali-7 = Kalirin-7; mGluR = metabotropic glutamate receptor; SPAR $=$ spineassociated RapGAP; IP3R = IP3 receptor; Cort $=$ Cortactin Synd $2=$ Syndecan -2 .

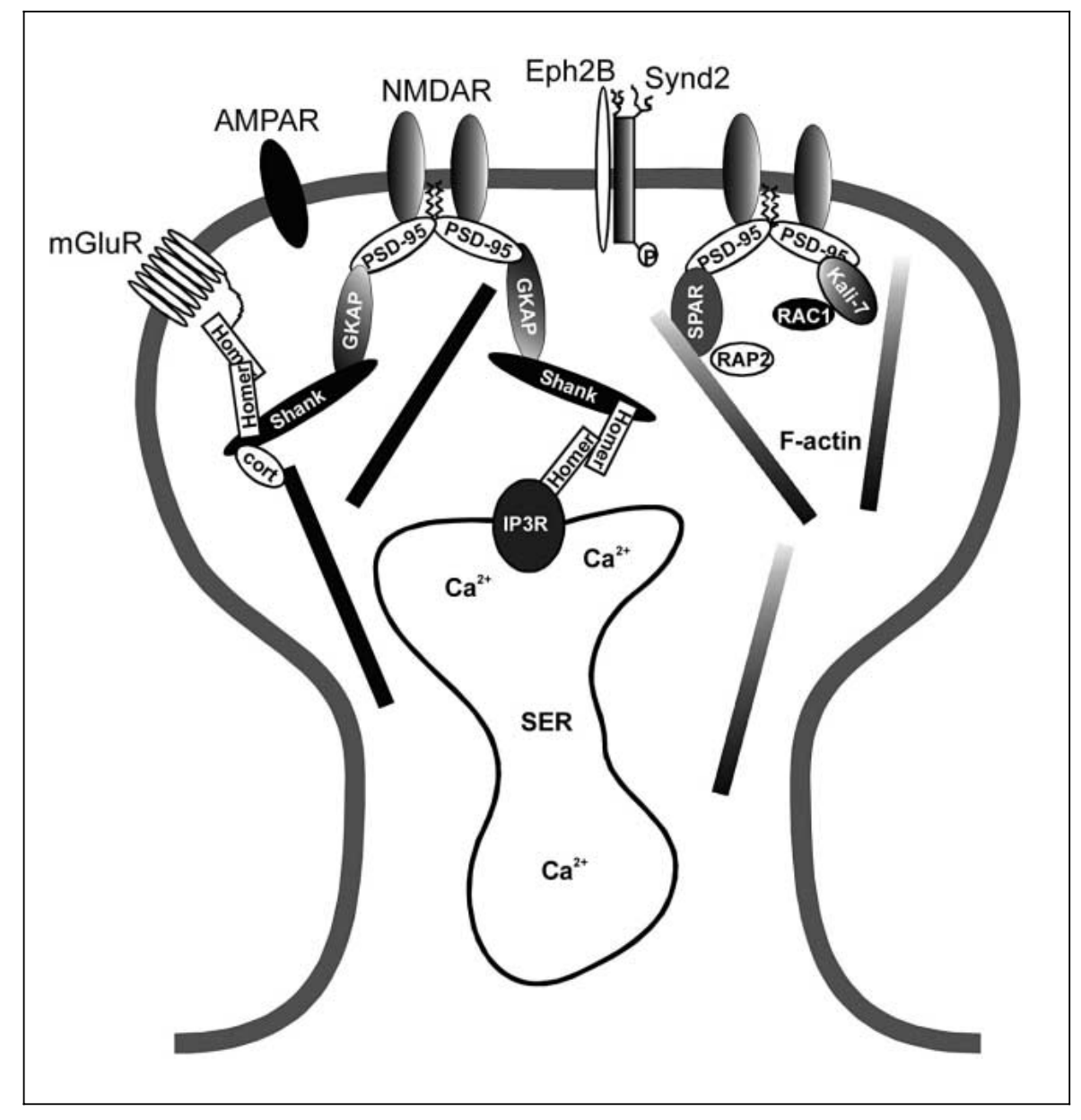

Transgenic mice overexpressing active Rac1 have an increased number of smaller dendritic spines in developing and mature cerebellar Purkinje cells, which form supernumerary synapses without modifying the dendritic trees [78]. A similar effect has been observed in pyramidal neurons transfected with constitutively active Rac1, which showed an increase in the number of filopodia-like processes and lamellipodia-like ruffles [79], whereas transfection with dominant-negative Rac1 reduced the number [80]. The involvement of Racl in spine formation has been further supported by Penzes et al. [81] who overexpressed Kalirin-7 (a guanine nucleotide exchange factor (GEF) for Rac1) in cultured cortical neurons and found that Kalirin-7 increased the number and size of spine-like protrusions. This effect is dependent on GEF activity because the overexpression of a Kalirin-7 mutant lacking GEF activity reduced the number of spines [81]. Interestingly, by binding to PSD-95 (and other PDZ domain-containing proteins) Kalirin-7 remains concen- trated to the postsynapse compartment where its activity is required, whereas a mutant that is unable to interact with PDZ proteins remains in the cell soma and induces the local formation of aberrant filopodial neuritis [81]. The effect of RhoA on dendrite spines is less clear. Tashiro et al. [80] showed that the overexpression of constitutively active RhoA can reduce the number of spines only in a subset of neurons whereas the inhibition of Rho activity may lead to the formation of supernumerary spines or the elongation of spine necks. It has been proposed that Rac and Rho signaling might antagonize the molecular mechanisms regulating spine formation and/or growth [80].

Another PSD-95 and actin-binding protein, SPAR, has been found to be involved in regulating spine shape [74]. SPAR is a GTPase-activating protein (GAP) for Rap, binds to the GK domain of PSD-95 and is enriched in spines. In COS-7 cells SPAR dramatically reorganizes Factin into large aggregates, dispersed clusters or smaller 
well-defined star-like clusters. PSD-95, which binds to SPAR with the GK domain, is recruited to these clusters. SPAR seems to bind directly to actin through two distinct actin-interacting domains (Act1 and Act2), which are separated by the GAP domain. The overexpression of SPAR in neurons causes the enlargement and elaboration of spine heads, thus making the spines more irregular, thorny and multilobed. SPAR-enlarged spines are also frequently associated with multiple synaptic contacts and, as many of them appear to be branched, they might be dividing. Three SPAR domains are required to induce an increase in the size of spine heads: the GAP domain, the second actin-binding domain (Act2), and the domain that binds to PSD-95 (GK-binding domain). The overexpression of a dominant-negative SPAR mutant lacking RapGAP activity causes an elongation and thinning of spines, some of which resemble filopodial-like structures [74]. These results indicate that the SPAR modulation of Rap GTPases plays a regulatory role on the actin cytoskeleton and changes spine shape.

Not only Rap 2 but also Ras is a component of the postsynaptic NMDA receptor complex. Indeed filopodia can be induced in cultured neurons by means of multiple depolarizing stimuli and this effect depends on activation of the Ras/MAPK pathway [82]. In conclusion Rac1, Rap2 and Ras together with their regulatory enzymes, are components of the postsynaptic NMDA receptor complex [83] linking receptor-mediated signals to actin dynamics. What could still remain to be discovered are the possible specific effectors of spine actin.

It is known that some of the receptors and scaffold proteins localized to dendritic spines are involved in spine morphogenesis. One of these is a cell-surface heparin-sulfate proteoglycan, called syndecan-2. The overexpression of syndecan-2 in hippocampal neurons accelerates the maturation of dendritic spines [84]. Interestingly, EphB2 (Eph family receptor) phosphorylates syndecan-2 on two cytoplasmic tyrosines, and this phosphorylation is required for the localization of the two proteins to developing spines and their maturation [85]. The idea is that EphB2, activated by ephrinB binding, phosphorylates the cytoplasmic tail of syndecan-2 and, in the process, the two proteins physically associate in clusters that lead to spine formation [85].

Among the PSD proteins, PDZ domain-containing scaffold proteins are believed to represent a molecular interface between glutamate receptors in synaptic membrane and spine cytoskeleton [21, 23]. It is consequently logical to think that some of these proteins may also link glutamate receptor activation to spine actin dynamics.
The overexpression of PSD95, which binds directly to the NR2 subunits of the NMDA receptors, increases the number and size of spines in hippocampal cultured neurons [86]. The overexpression of Shank, which links the NMDA receptor and the metabotropic glutamate receptor (mGluR) complexes through multiple protein interactions [77, 87], promotes the maturation of mushroomshaped spines in developing hippocampal neurons, and increases the size of spine heads in mature neurons without affecting spine number [87]. The enlargement of spines by Shank depends on and cooperates with Homer, a protein that also binds to mGluRs and inositol-1,4,5trisphosphate receptors $\left(\mathrm{InsP}_{3} \mathrm{R}\right)$. Indeed, Shank and Homer seem to mediate the recruitment of $\operatorname{InsP}_{3} \mathrm{R}$ (and presumably SER) to dendritic spines. Dominant-negative Shank mutants reduce spine density, possibly by decreasing the stability of affected spines or by inhibiting spine formation. Interestingly, postsynaptic overexpression of PSD-95 or Shank/Homer significantly enhances presynaptic function in addition to spine enlargement [86, 87], this emphasizes the close functional relationship between the two sides of the synapse.

\section{Dendritic Spine Motility and Morphological Modification}

Spine motility was originally proposed by Blomberg et al. [88] and Crick [89] but was first demonstrated by Fischer et al. [90]. Using time-lapse imaging and fluorescent proteins, considerable spine motility over a time scale of seconds to minutes has been documented in dissociated cultures [90-92], brain slices [11] and in vivo [93]. Motility is developmentally regulated, and is more pronounced during the critical period [11, 93-95]. Spine motility is actin-dependent, involves the remodelling of the actin cytoskeleton in the spine $[11,90]$, and is inhibited by volatile anesthetics [96]. At least in cultured neurons, the activity-dependent suppression of spine movement, has been found to inversely correlate with developmental age and contact with active presynaptic terminals, and is stimulated by inhibiting the basal activity with tetrodotoxin [95]. In brain slices, others have failed to detect any change in spine motility after the blockade or stimulation of neuronal activity, or in correlation with presynaptic contact $[11,97]$. This difference can be explained by the different experimental preparations: dispersed hippocampal cultures [90, 95, 96] versus hippocampal slices [11, 51, 97]. Interestingly, a recent study using GFP-transfected pyramidal neurons in the somato- 
sensory cortex found that spine motility is sensitive to input deprivation, but only during the period of peak neocortical synaptogenesis, thus suggesting the presence of a link between experience-driven synaptogenesis and spine motility [93].

There is evidence that actin-based motility is controlled by synaptic activity [91, 92]. The activation of either AMPA or NMDA receptors greatly inhibits spine actin dynamics and actin-based protrusive activity from the spine head, and the spine becomes more rounded and regular [91]. In this case, the inhibition of spine motility by AMPA receptors was dependent on postsynaptic membrane depolarization and calcium influx through voltageactivated channels [91]. Using a clever and technically advanced system to stimulate individual neurons, Colicos et al. [92] were able to show coordinated presynaptic and postsynaptic actin motility after tetanus stimulation. On the postsynaptic side, actin expands laterally outward from the central core, and new filopodia-like protrusions emerge that are eventually contacted by new presynaptic puncta of actin that become functional in a period of hours [92]. These morphological modifications are reminiscent of what can be observed during developmental synaptogenesis [50]. Finally, another fast and rapid movement of spines has been described by Korkotian and Segal [98], who found that they produce a tiny and rapid 'twitch' under back-propagating action potential and coincide with a transient increase in the intraspine calcium concentration. This fast movement is apparently independent on the age of the neurons and is present on spines contacted by an active presynaptic terminal [98].

However, although all of these findings indicate that spines are constantly moving and change morphology under physiological conditions, the functional significance of spine motility occurring over seconds or minutes is still completely obscure.

As mentioned above glutamate receptor stimulation plays a role in controlling spine motility but also regulates spine numbers. NMDA application to hippocampal cultures causes an almost complete collapse of dendritic spines and removes actin from the spine head [99]. Calcium and calcineurin seem to be involved in regulating spine stability: the NMDA-induced loss of spine actin and spine collapse is reduced in the presence of calcineurin, a calcium/calmodulin-dependent phosphatase [99]. On the contrary a low level of AMPA receptor activation with an intensity similar to that of spontaneous neurotransmitter release is required to maintain spine numbers in hippocampus organotypic cultures [100]. As described above AMPA receptor stimulation can also stop rapid spine movements by stimulating calcium influx [91], but it has also been reported that the release of intracellular calcium by caffeine stimulates spine elongation [101]. In order to reconcile these data, we can image a bimodal relationship between calcium concentration and spine growth that is similar to what has been invoked to explain the different calcium requirements of LTD and LTP. A moderate transient increase in spine calcium provided by SER release, or through voltage-gated calcium channels mediated by AMPA receptor stimulation is necessary to promote spine stability and growth, whereas the higher concentrations of spine calcium induced by a prolonged activation of NMDA receptors induce spine shrinkage or collapse [102-104].

But the main question concerning spine plasticity is whether LTP or LTD is the expression of morphological modification in spine structure [105] and a number of electron microscopy studies have been carried out to test this hypothesis. The first report on the effect of LTP on spine morphology was published in 1975 by Fifkova and Van Harrefeld [106] who used a similar experimental protocol to that used a few years before by Bliss and Lømo [107] when they discovered LTP in the dentate gyrus. In this and a subsequent study [106], the authors describe a significant increase in spine area and volume from $2 \mathrm{~min}$ to $23 \mathrm{~h}$ after LTP induction with a peak at $10-60 \mathrm{~min}$. Together with the observation that the spine neck becomes wider and shorter, these data suggest that tetanization is able to increase synapse size by increasing spine volume and recruiting an actin cytoskeleton, and that these changes last for hours [108, 109]. In a controlled series of more electrophysiological studies, Desmond and Levy [110] showed that LTP increases the density of large spines that have spinules or U-shaped profiles, and decreases the number of simple and ellipsoid spine profiles. The PSD area was also modified, with the total PSD surface area per unit volume of concave spines increasing significantly, whereas that of the non-concave spines decreased and an increase in the mean PSD length was observed for at least $60 \mathrm{~min}[30,31,110,111]$. Together, the studies of Fifkova et al. [106, 108, 109] and Desmond and Levy $[110,111]$ suggest that LTP induces the morphological modification of existing spines and synapses without the formation of new entities.

Conflicting results can be found in the literature concerning changes in spine number after LTP or exposure in an enriched or altered sensory environment. Trommald et al. [112] Andersen et al. [113] used three-dimensional reconstructions of serial EM micrographs, and observed an up to $50 \%$ increase in spine numbers, as well as 
changes in the diameter of the spine neck and an increase in the so-called bifurcated spines, after inducing LTP in the dentate gyrus. They also found a small but significant increase in spine density in the CA1 region of the hippocampus of rats exposed to an enhanced sensory environment $[114,115]$, but others $[6,40,116]$ found no changes in absolute spine number. However, some of these studies used the CA1 region instead of the dentate gyrus, or stimulated brain slices instead of in vivo stimulation. All of these studies were also based on statistical comparisons of two samples, whereas a better way would be to observe single spine in living tissue and show morphological changes in real time. Three seminal studies in this direction were published in 1999. Two of these used two-photon microscopy and brain slices. Maletic-Savatic et al. [117] visualized individual neurons infected by sindbisvirus-eGFP constructs, and found the outgrowth of dendritic protrusions similar to filopodia (often more than $4 \mu \mathrm{m}$ longer) after a strong tetanus-inducing LTP. The formation of these new protrusions that may turn into spine-like structures could be blocked by APV, the NMDA and LTP blocker [117]. In a more sophisticated way, in an attempt to localize where the potential morphological changes may occur, Engert and Bonhoeffer [118] showed a close correlation between successful functional synaptic enhancement and the generation of new spines.

Using another elegant approach, the same question was addressed by means of an EM analysis of spines from neurons in which an LTP had been previously induced [38]. This technique was able to select where morphological changes can be expected to occur in stimulated synapses by accumulating an EM-visible calcium precipitate in a postsynaptic spine that had just been subjected to a strong stimulus. Scrutinizing these spines for morphological changes, the authors found that, in many cases, there were pairs or triplets of labelled spines making contact with the same presynaptic terminal, or what were called 'same-dendrite, multiple synapse boutons' (sdMSBs). Similar ultrastructure modifications were observed by the same authors after short anoxic-hypoglycemic episodes and NMDA receptor activation in brain slices [119]. This may be the result of a rapid morphogenetic sequence of events after LTP-inducing stimulation that leads to PSD segmentation and spine splitting [37, 38]. However, using classical EM reconstruction, Fiala et al. [120] have more recently suggested that the sdMSBs formed after LTP are not due to spine splitting but probably the growth of new spines or the maturation of filopodia-like structures.
In conclusion although there seems to be a correlation between LTP and spine morphological modifications, there is no direct proof that these morphological changes contribute to synaptic strength as well as to the generation of potential new contact sites.

\section{Conclusions and Open Questions}

The molecular exploration of spines is just at its beginning, but it is not surprising that a number of structural proteins and signaling pathways are involved. Spine structure is complex and dynamically regulated by different factors over short and long time scales. Many fundamental issues must still be addressed in order to understand spine function in brain physiology: for instance, although several actin-binding proteins are known to be involved in spine actin dynamics, none of them seems to be dedicated to dendritic spine regulation. The identification of specific actin modulators localized to spines might increase the possibility of analyzing spine function by mean of a genetic approach. Alternatively it will be important to identify intracellular or extracellular factors that determine spine formation or absence in various neuron types. Another important question is to determine the relationship between spine shape and function in detail, as this will perhaps allow us to adjust spine morphology in order to make a neuron work or survive better. A number of cognitive disorders are associated with subtle spine malformations, such as changes in spine length, distribution, number or morphology, but still a detailed morphological, physiological and biochemical analysis has to be made in order to correlate clinical phenotypes and spine abnormalities. All of these key questions and others will be addressed in the near future using new and advanced technologies, this making an exciting and rapidly developing field. 


\section{References}

1 Harris K, Kater S: Dendritic spines: Cellular specializations imparting both stability and flexibility to synaptic function. Annu Rev Neurosci 1994; 17:341-371.

2 Harris K: Structure, development, and plasticity of dendritic spines. Curr Opin Neurobiol 1999;9:343-348.

3 Ramon y Cajal S: Sur la structure de l'écorce cérébrale de quelques mammifères. Cellule 1891;7:125-176.

4 Young JZ: The giant fibre synapse of Loligo. Brain Res 1973;57:457-460.

5 Hering H, Sheng M: Dendritic spines: Structure, dynamics and regulation. Nat Rev Neurosci 2001;2:880-888.

6 Chang FL, Greenough WT: Transient and enduring morphological correlates of synaptic activity and efficacy change in the rat hippocampal slice. Brain Res 1984;309:35-46.

7 Peters A, Kaiserman-Abramof IR: The small pyramidal neuron of the rat cerebral cortex. The perikaryon, dendrites and spines. Am J Anat 1970;127:321-355.

8 Harris KM, Jensen FE, Tsao B: Three-dimensional structure of dendritic spines and synapses in rat hippocampus (CA1) at postnatal day 15 and adult ages: Implications for the maturation of synaptic physiology and long-term potentiation. J Neurosci 1992;12:2685-2705.

9 Spacek J, Harris KM: Three-dimensional organization of cell adhesion junctions at synapses and dendritic spines in area CA1 of the rat hippocampus. J Comp Neurol 1998:393:58-68.

10 Parnass Z, Tashiro A, Yuste R: Analysis of spine morphological plasticity in developing hippocampal pyramidal neurons. Hippocampus 2000;10:561-568.

11 Dunaevsky A, Tashiro A, Majewska A, Mason C, Yuste R: Developmental regulation of spine motility in the mammalian central nervous system. Proc Natl Acad Sci USA 1999;96:1343813443.

12 Ventura R, Harris KM: Three-dimensional relationships between hippocampal synapses and astrocytes. J Neurosci 1999;19:6897-6906.

13 Jones EG, Powell TP: Morphological variations in the dendritic spines of the neocortex. J Cell Sci 1969;5:509-529.

14 Knott GW, Quairiaux C, Genoud C, Welker E: Formation of dendritic spines with GABAergic synapses induced by whisker stimulation in adult mice. Neuron 2002;34:265-273.

15 Spacek J, Harris K: Three-dimensional organization of smooth endoplasmic reticulum in hippocampal CA1 dendrites and dendritic spines of the immature and mature rat. J Neurosci 1997; 17:190-203

16 Westrum LE, Jones DH, Gray EG, Barron J: Microtubules, dendritic spines and spine appratuses. Cell Tissue Res 1980;208:171-181.

17 Burgoyne RD, Barron J, Geisow MJ: Cytochemical localisation of calcium binding sites in adrenal chromaffin cells and their relation to secretion. Cell Tissue Res 1983;229:207-217.
18 Andrews SB, Leapman RD, Landis DM, Reese TS: Activity-dependent accumulation of calcium in Purkinje cell dendritic spines. Proc Natl Acad Sci USA 1988;85:1682-1685.

19 Spacek J: Three-dimensional analysis of dendritic spines. II. Spine apparatus and other cytoplasmic components. Anat Embryol 1985; 171:235-243.

20 Steward O, Reeves TM: Protein-synthetic machinery beneath postsynaptic sites on CNS neurons: Association between polyribosomes and other organelles at the synaptic site. J Neurosci 1988;8:176-184.

21 Sheng M, Pak DTS: Ligand-gated ion channel interactions with cytoskeletal and signaling proteins. Annu Rev Physiol 2000;62:755-778.

22 Kennedy MB: Signal-processing machines at the postsynaptic density. Science 2000;290: 750-754.

23 Sheng M, Sala C: PDZ domains and the organization of supramolecular complexes. Annu Rev Neurosci 2001;24:1-29.

24 Nusser Z, Lujan R, Laube G, Roberts JD, Molnar E, Somogyi P: Cell type and pathway dependence of synaptic AMPA receptor number and variability in the hippocampus. Neuron 1998;21:545-559.

25 Racca C, Stephenson FA, Streit P, Roberts JD, Somogyi P: NMDA receptor content of synapses in stratum radiatum of the hippocampal CA1 area. J Neurosci 2000;20:2512-2522.

26 Takumi Y, Ramirez-Leon V, Laake P, Rinvik E, Ottersen OP: Different modes of expression of AMPA and NMDA receptors in hippocampal synapses. Nat Neurosci 1999;2:618-624.

27 Schikorski T, Stevens CF: Quantitative ultrastructural analysis of hippocampal excitatory synapses. J Neurosci 1997; 17:5858-5867.

28 Murthy VN, Sejnowski TJ, Stevens CF: Heterogeneous release properties of visualized individual hippocampal synapses. Neuron 1997; 18:599-612.

29 Harris KM, Stevens JK: Dendritic spines of CA 1 pyramidal cells in the rat hippocampus: Serial electron microscopy with reference to their biophysical characteristics. J Neurosci 1989;9:2982-2997.

30 Desmond NL, Levy WB: Changes in the postsynaptic density with long-term potentiation in the dentate gyrus. J Comp Neurol 1986;253: 476-482.

31 Desmond NL, Levy WB: Changes in the numerical density of synaptic contacts with longterm potentiation in the hippocampal dentate gyrus. J Comp Neurol 1986;253:466-475.

32 Buchs PA, Muller D: Induction of long-term potentiation is associated with major ultrastructural changes of activated synapses. Proc Natl Acad Sci USA 1996;93:8040-8045.

33 Hayashi Y, Shi SH, Esteban JA, Piccini A, Poncer JC, Malinow R: Driving AMPA receptors into synapses by LTP and CaMKII: Requirement for GluR1 and PDZ domain interaction. Science 2000;287:2262-2267.
34 Passafaro M, Piech V, Sheng M: Subunit-specific temporal and spatial patterns of AMPA receptor exocytosis in hippocampal neurons. Nat Neurosci 2001;4:917-926.

35 Luscher C, Nicoll RA, Malenka RC, Muller D: Synaptic plasticity and dynamic modulation of the postsynaptic membrane. Nat Neurosci 2000;3:545-550.

36 Shi S, Hayashi Y, Esteban JA, Malinow R: Subunit-specific rules governing AMPA receptor trafficking to synapses in hippocampal pyramidal neurons. Cell 2001;105:331-343.

37 Toni N, Buchs PA, Nikonenko I, Povilaitite P Parisi L, Muller D: Remodeling of synaptic membranes after induction of long-term potentiation. J Neurosci 2001;21:6245-6251.

38 Toni N, Buchs PA, Nikonenko I, Bron CR, Muller D: LTP promotes formation of multiple spine synapses between a single axon terminal and a dendrite. Nature 1999;402:421-425.

39 Sorra KE, Fiala JC, Harris KM: Critical assessment of the involvement of perforations, spinules, and spine branching in hippocampal synapse formation. J Comp Neurol 1998;398.

40 Sorra KE, Harris KM: Stability in synapse number and size at $2 \mathrm{~h}$ after long-term potentiation in hippocampal area CA1. J Neurosci 1998;18:658-671.

41 Trommald M, Hulleberg G: Dimensions and density of dendritic spines from rat dentate granule cells based on reconstructions from serial electron micrographs. J Comp Neurol 1997;377:15-28.

42 Napper RM, Harvey RJ: Quantitative study of the Purkinje cell dendritic spines in the rat cerebellum. J Comp Neurol 1988;274:158-167.

43 Harris KM, Stevens JK: Dendritic spines of rat cerebellar Purkinje cells: Serial electron microscopy with reference to their biophysical characteristics. J Neurosci 1988;8:4455-4469.

44 Papa M, Bundman MC, Greenberger V, Segal M: Morphological analysis of dendritic spine development in primary cultures of hippocampal neurons. J Neurosci 1995; 15:1-11.

45 Marin-Padilla M, Stibitz GR: Distribution of the apical dendritic spines of the layer $\mathrm{V}$ pyramidal cells of the hamster neocortex. Brain Res 1968;11:580-592.

46 Valverde F: Apical dendritic spines of the visual cortex and light deprivation in the mouse. Exp Brain Res 1967;3:337-352.

47 Jacobs B, Schall M, Prather M, Kapler E, Driscoll L, et al: Regional dendritic and spine variation in human cerebral cortex: A quantitative Golgi study. Cereb Cortex 2001;11:558-571.

48 Elston GN: Pyramidal cells of the frontal lobe: all the more spinous to think with. J Neurosci 2000;20:RC95.

49 Nimchinsky EA, Oberlander AM, Svoboda K: Abnormal development of dendritic spines in FMR1 knock-out mice. J Neurosci 2001;21: 5139-5146.

50 Fiala JC, Feinberg M, Popov V, Harris KM: Synaptogenesis via dendritic filopodia in developing hippocampal area CA1. J Neurosci 1998;18:8900-8911. 
51 Dailey ME, Smith SJ: The dynamics of dendritic structure in developing hippocampal slices. J Neurosci 1996;16:2983-2994.

52 Ziv NE, Smith SJ: Evidence for a role of dendritic filopodia in synaptogenesis and spine formation. Neuron 1996;17:91-102.

53 Adams I, Jones DG: Quantitative ultrastructural changes in rat cortical synapses during early-, mid- and late-adulthood. Brain Res 1982;239:349-363.

54 Marrs GS, Green SH, Dailey ME: Rapid formation and remodeling of postsynaptic densities in developing dendrites. Nat Neurosci 2001;4:1006-1013.

55 Okabe S, Urushido T, Konno D, Okado H, Sobue K: Rapid redistribution of the postsynaptic density protein PSD-Zip45 (Homer 1c) and its differential regulation by NMDA receptors and calcium channels. J Neurosci 2001;21 9561-9571.

56 Sabatini BL, Maravall M, Svoboda K: $\mathrm{Ca}(2+)$ signaling in dendritic spines. Curr Opin Neurobiol 2001;11:349-356.

57 Nimchinsky EA, Sabatini BL, Svoboda K Structure and function of dendritic spines. Annu Rev Physiol 2002;64:313-353.

58 Svoboda K, Tank DW, Denk W: Direct measurement of coupling between dendritic spines and shafts. Science 1996;272:716-719.

59 Majewska A, Brown E, Ross J, Yuste R: Mechanisms of calcium decay kinetics in hippocampal spines: Role of spine calcium pumps and calcium diffusion through the spine neck in biochemical compartmentalization. J Neurosci 2000;20:1722-1734.

60 Korkotian E, Segal M: Structure-function relations in dendritic spines: Is size important? Hippocampus 2000;10:587-595.

61 Yuste R, Majewska A, Holthoff K: From form to function: calcium compartmentalization in dendritic spines. Nat Neurosci 2000;3:653659.

62 Majewska A, Tashiro A, Yuste R: Regulation of spine calcium dynamics by rapid spine motility. J Neurosci 2000;20:8262-8268.

63 Sabatini BL, Oertner TG, Svoboda K: The life cycle of $\mathrm{Ca}(2+)$ ions in dendritic spines. Neuron 2002;33:439-452.

64 Holthoff K, Tsay D, Yuste R: Calcium dynamics of spines depend on their dendritic location. Neuron 2002;33:425-437.

65 Irwin SA, Patel B, Idupulapati M, Harris JB, Crisostomo RA, et al: Abnormal dendritic spine characteristics in the temporal and visua cortices of patients with fragile-X syndrome: A quantitative examination. Am J Med Genet 2001;98:161-167.

66 Hinton VJ, Brown WT, Wisniewski K, Rudelli $\mathrm{RD}$ : Analysis of neocortex in three males with the fragile X syndrome. Am J Med Genet 1991; 41:289-294.

67 Comery TA, Harris JB, Willems PJ, Oostra BA, Irwin SA, et al: Abnormal dendritic spines in fragile $\mathrm{X}$ knockout mice: Maturation and pruning deficits. Proc Natl Acad Sci USA 1997 94:5401-5404.
68 Das S, Sasaki YF, Rothe T, Premkumar LS, Takasu M, et al: Increased NMDA current and spine density in mice lacking the NMDA receptor subunit NR3A. Nature 1998;393:377-381.

69 Feng J, Yan Z, Ferreira A, Tomizawa K, Liauw JA, et al: Spinophilin regulates the formation and function of dendritic spines. Proc Natl Acad Sci USA 2000;97:9287-9292.

70 Rao A, Craig AM: Signaling between the actin cytoskeleton and the postsynaptic density of dendritic spines. Hippocampus 2000;10:527541.

71 Wyszynski M, Kharazia V, Shanghvi R, Rao A, Beggs AH, et al: Differential regional expression and ultrastructural localization of $\alpha$-actinin-2, a putative NMDA receptor-anchoring protein, in rat brain. J Neurosci 1998;18:13831392.

72 Hayashi K, Shirao T: Change in the shape of dendritic spines caused by overexpression of drebrin in cultured cortical neurons. J Neurosci 1999;19:3918-3925.

73 Allen PB, Ouimet CC, Greengard P: Spinophilin, a novel protein phosphatase 1 binding protein localized to dendritic spines. Proc Natl Acad Sci USA 1997;94:9956-9961.

74 Pak DT, Yang S, Rudolph-Correia S, Kim E, Sheng M: Regulation of dendritic spine morphology by SPAR, a PSD-95-associated RapGAP. Neuron 2001;31:289-303.

75 Matsuoka Y, Li X, Bennett V: Adducin is an in vivo substrate for protein kinase $\mathrm{C}$ : Phosphorylation in the MARCKS-related domain inhibits activity in promoting spectrin-actin complexes and occurs in many cells, including dendritic spines of neurons. J Cell Biol 1998;142:485497.

76 Mundel P, Heid HW, Mundel TM, Kruger M, Reiser J, Kriz W: Synaptopodin: An actin-associated protein in telencephalic dendrites and renal podocytes. J Cell Biol 1997;139:193204.

77 Naisbitt S, Kim E, Tu JC, Xiao B, Sala C, et al: Shank, a novel family of postsynaptic density proteins that binds to the NMDA receptor/ PSD-95/GKAP complex and cortactin. Neuron 1999;23:569-582.

78 Luo L, Hensch TK, Ackerman L, Barbel S, Jan LY, Jan YN: Differential effects of the Rac GTPase on Purkinje cell axons and dendritic trunks and spines. Nature 1996;379:837-840.

79 Nakayama AY, Harms MB, Luo L: Small GTPases Rac and Rho in the maintenance of dendritic spines and branches in hippocampal pyramidal neurons. J Neurosci 2000;20:53295338.

80 Tashiro A, Minden A, Yuste R: Regulation of dendritic spine morphology by the rho family of small GTPases: antagonistic roles of Rac and Rho. Cereb Cortex 2000;10:927-938.

81 Penzes P, Johnson RC, Sattler R, Zhang X, Huganir RL, et al: The neuronal Rho-GEF Kalirin-7 interacts with PDZ domain-containing proteins and regulates dendritic morphogenesis. Neuron 2001;29:229-242.
82 Wu GY, Deisseroth K, Tsien RW: Spaced stimuli stabilize MAPK pathway activation and its effects on dendritic morphology. Nat Neurosci 2001;4:151-158.

83 Husi H, Ward M, Choudhary J, Blackstock W, Grant S: Proteomic analysis of NMDA receptor-adhesion protein signaling complexes. Nat Neurosci 2000;3:661-669.

84 Ethell I, Yamaguchi Y: Cell surface heparan sulfate proteoglycan syndecan-2 induces the maturation of dendritic spines in rat hippocampal neurons. J Cell Biol 1999;144:575586

85 Ethell IM, Irie F, Kalo MS, Couchman JR, Pasquale EB, Yamaguchi Y: EphB/syndecan-2 signaling in dendritic spine morphogenesis. Neuron 2001:31:1001-1013.

86 El-Husseini AE, Schnell E, Chetkovich DM, Nicoll RA, Bredt DS: PSD-95 involvement in maturation of excitatory synapses. Science 2000;290:1364-1368.

87 Sala C, Piech V, Wilson NR, Passafaro M, Liu $\mathrm{G}$, Sheng $\mathrm{M}$ : Regulation of dendritic spine morphology and synaptic function by Shank and Homer. Neuron 2001;31:115-130.

88 Blomberg F, Cohen RS, Siekevitz P: The structure of postsynaptic densities isolated from dog cerebral cortex. II. Characterization and arrangement of some of the major proteins within the structure. J Cell Biol 1977;74:204-225.

89 Crick F: Do dendritic spines twitch? Trends Neurosci 1982;5:44-46.

90 Fischer M, Kaech S, Knutti D, Matus A: Rapid actin-based plasticity in dendritic spines. Neuron 1998;20:847-854.

91 Fischer M, Kaech S, Wagner U, Brinkhaus H, Matus A: Glutamate receptors regulate actinbased plasticity in dendritic spines. Nat Neurosci 2000;3:887-894.

92 Colicos MA, Collins BE, Sailor MJ, Goda Y: Remodeling of synaptic actin induced by photoconductive stimulation. Cell 2001;107:605616.

93 Lendvai B, Stern EA, Chen B, Svoboda K: Experience-dependent plasticity of dendritic spines in the developing rat barrel cortex in vivo. Nature 2000;404:876-881.

94 Matus A, Brinkhaus H, Wagner U: Actin dynamics in dendritic spines: a form of regulated plasticity at excitatory synapses. Hippocampus 2000;10:555-560.

95 Korkotian E, Segal M: Regulation of dendritic spine motility in cultured hippocampal neurons. J Neurosci 2001;21:6115-6124.

96 Kaech S, Brinkhaus H, Matus A: Volatile anesthetics block actin-based motility in dendritic spines. Proc Natl Acad Sci USA 1999;96: 10433-10437.

97 Dunaevsky A, Blazeski R, Yuste R, Mason C: Spine motility with synaptic contact. Nat Neurosci 2001;4:685-686.

98 Korkotian E, Segal M: Spike-associated fast contraction of dendritic spines in cultured hippocampal neurons. Neuron 2001;30:751-758.

99 Halpain S, Hipolito A, Saffer L: Regulation of F-actin stability in dendritic spines by glutamate receptors and calcineurin. J. Neurosci. 1998;18:9835-9844. 
100 McKinney RA, Capogna M, Durr R, Gahwiler BH, Thompson SM: Miniature synaptic events maintain dendritic spines via AMPA receptor activation. Nat Neurosci 1999;2:4449.

101 Korkotian E, Segal M: Release of calcium from stores alters the morphology of dendritic spines in cultured hippocampal neurons. Proc Natl Acad Sci USA 1999;96:12068-12072.

102 Harris KM: Calcium from internal stores modifies dendritic spine shape. Proc Natl Acad Sci USA 1999;96:12213-12215.

103 Segal M, Korkotian E, Murphy DD: Dendritic spine formation and pruning: common cellular mechanisms? Trends Neurosci 2000;23: 53-57.

104 Korkotian E, Segal M: Bidirectional regulation of dendritic spine dimensions by glutamate receptors. Neuroreport 1999;10:28752877.

105 Yuste R, Bonhoeffer T: Morphological changes in dendritic spines associated with long-term synaptic plasticity. Annu Rev Neurosci 2001;24:1071-1089.

106 Fifkova E, Van Harreveld A: Long-lasting morphological changes in dendritic spines of dentate granular cells following stimulation of the entorhinal area. J Neurocytol 1977;6 211-230.
107 Bliss TV, Lomo T: Long-lasting potentiation of synaptic transmission in the dentate area of the anaesthetized rabbit following stimulation of the perforant path. J Physiol 1973; 232:331-356

108 Fifkova E: Actin in the nervous system. Brain Res 1985;356:187-215.

109 Fifkova E, Anderson CL: Stimulation-induced changes in dimensions of stalks of dendritic spines in the dentate molecular layer. Exp Neurol 1981;74:621-627.

110 Desmond NL, Levy WB: Synaptic correlates of associative potentiation/depression: An ultrastructural study in the hippocampus. Brain Res 1983;265:21-30.

111 Desmond NL, Levy WB: Synaptic interface surface area increases with long-term potentiation in the hippocampal dentate gyrus. Brain Res 1988;453:308-314.

112 Trommald M, Hulleberg G, Andersen P: Long-term potentiation is associated with new excitatory spine synapses on rat dentate granule cells. Learn Mem 1996;3:218-228.

113 Andersen P, Blackstad T, Hulleberg G, Trommald M, Vaaland JL: Dimensions of dendritic spines of rat dentate granule cells during long-term potentiation. J Physiol 1987;390: P264.
114 Moser MB, Trommald M, Andersen P: An increase in dendritic spine density on hippocampal CA1 pyramidal cells following spatial learning in adult rats suggests the formation of new synapses. Proc Natl Acad Sci USA 1994;91:12673-12675.

115 Moser MB, Trommald M, Egeland T, Andersen P: Spatial training in a complex environment and isolation alter the spine distribution differently in rat CA1 pyramidal cells. J Comp Neurol 1997;380:373-381.

116 Lee KS, Schottler F, Oliver M, Lynch G: Brief bursts of high-frequency stimulation produce two types of structural change in rat hippocampus. J Neurophysiol 1980;44:247-258.

117 Maletic-Savatic M, Malinow R, Svoboda K: Rapid dendritic morphogenesis in CA1 hippocampal dendrites induced by synaptic activity. Science 1999;283:1923-1927.

118 Engert F, Bonhoeffer T: Dendritic spine changes associated with hippocampal longterm synaptic plasticity. Nature 1999;399: 66-70.

119 Jourdain P, Nikonenko I, Alberi S, Muller D: Remodeling of hippocampal synaptic networks by a brief anoxia- hypoglycemia. J Neurosci 2002;22:3108-3116.

120 Fiala JC, Allwardt B, Harris KM: Dendritic spines do not split during hippocampal LTP or maturation. Nat Neurosci 2002;5:297298. 